\title{
An Artificial Neural Network Approach for Predicting Customer Loyalty: A Case Study in an Online Travel Agency
}

\author{
M. Mujiya Ulkhaq, Arga Adyatama, Finsaria Fidiyanti, Riyan Rozaq, and M. Fauzan M. Raharjo
}

\begin{abstract}
The objective of this study is to predict the customer loyalty of an online travel agency (OTA) using the artificial neural network (ANN) approach. Six website quality dimensions, i.e., ease of use, security/privacy, information/ content, responsiveness, visual appeal, and fulfillment were used as independent variables to measure the service quality; while the dependent variables were represented by customers' willingness to recommend the services, to revisit/reuse the services in the future, and to give positive referral to others. A case study was conducted in an Indonesian-based OTA. The results of the ANN then were compared with the logistic regression model. It was found that the ANN models can predict customer loyalty better than the logistic regression model as they have higher accuracy and lower root mean square error. This study is expected not only to give a contribution to the literature towards customers' loyalty prediction but also to give an insight to the managers of OTA about how to pursue customer loyalty.
\end{abstract}

Index Terms-Artificial neural network, customer loyalty, logistic regression, online travel agency.

\section{INTRODUCTION}

One of the central points of the marketing activities of an enterprise is often viewed in terms of development, maintenance, or enhancement of customers' loyalty towards its products, both goods and services [1]. Customer loyalty constitutes a fundamental goal for strategic market planning [2] and represents a vital basis for developing a sustainable competitive advantage. In this increasing global competition with rapid market entry of innovative products, on the one hand, and maturity conditions in certain product markets, on the other, the mission of managing customer loyalty has emerged as a pivotal managerial challenge [1].

Customer loyalty can be defined as the willingness of a customer to continue consuming a specific product or service [3]. It involves the likelihood of future consumption, continued service contracts, reduced possibility of brand change, and positive public recommendation [4]. Many previous studies showed that higher customer loyalty often leads to higher profitability, see for example [5]-[8]. The profitability of a firm increased proportionally with the

Manuscript received November 11, 2018; revised August 5, 2019.

M. M. Ulkhaq, A. Adyatama, F. Fidiyanti, R. Rozaq, and M. F. M. Raharjo are with the Department of Industrial Engineering, Diponegoro University, Semarang 50275 Indonesia (e-mails: ulkhaq@live.undip.ac.id, adyatama.arga@gmail.com, finsafidi@gmail.com, riyan.rozaq@gmail.com, fauzanmarantama9@gmail.com). number of loyal customers, and up to $60 \%$ of sales to new customers could be attributed to word-of-mouth referrals [8].

In this highly competitive market, the internet plays an important role in people's life. Some activities that used to be done traditionally (off-line), currently, can be done unconventionally (online). This phenomenon must bring a big change in people's lifestyle who demand everything could be done faster and easier than previously. This phenomenon occurs in almost every living activity, including shopping behavior.

Customers' activity in travelling is also changed, just like a shopping behavior. Currently, many people do not want to go to the traditional or physical or off-line travel agencies; they have switched with online travel agency (OTA), either by utilizing mobile application or by web application. In this business, customer loyalty is believed to be a primary goal since most of the OTA have reward programs which are designed to attract and retain the users. In Indonesia, the market value of online travel is estimated to reach 372 trillion IDR or 24.5 billion USD in 2025 [9]. It shows that an OTA must struggle in satisfying customers to foster a sense of customer loyalty. Therefore, this research attempted to predict the customer loyalty of an OTA.

There are several studies investigated the relationships between customer loyalty and website quality (e.g., [10]-[12]); hence, in this research, the dimensions of website quality were used as determinants to predict customer loyalty. To measure website quality, there are several scales used, such as SITEQUAL [13], Web-Qual 4.0 [14], WebQual ${ }^{\mathrm{TM}}$ [15], eTailQ [16], eTransQual [17], [18], as well as E-S-QUAL and E-RecS-QUAL scales [19], [20]. However, those scales are intended for general purposes, i.e., they are not intended to assess particular OTA's website quality. Therefore, in this study, the specific scale to assess website quality of OTA was used, which is adopted from the study of [10].

On the other side, customer loyalty is then represented by three dichotomous scaled questions of attitudinal measures of customer loyalty, i.e., suggesting the OTA to others, revisiting the services of the OTA, and providing a positive referral to others for the OTA. These attitudinal measures of customer loyalty are shown to be appropriate variables to measure customer psychological connection and intention to revisit the OTA in the future [3].

In this study, an artificial neural network (ANN) approach was used to predict customer loyalty. The ANN is a popular machine learning technique which is inspired by the neural 
network of human brain. The network is represented as a system of interconnected neurons that can compute various values from input information and can learn the intrinsic nature of patterns or processes from data sets. The ANN has been used by many studies as a tool for predicting, see for example [21]-[25]. The development of multi-layer concept enables ANN to be selected as a prediction tool besides others [22]. Briefly, the network models one input layer, one or several hidden layer(s), and one output layer [26], [27]. It has been developed as generalizations of mathematical models of human cognition or neural biology (see Section 2 for a brief description of the ANN).

The paper is structured as follows. In the following section, the research design is presented. It contains the dimensions of website quality that were used in this study and a brief explanation of the ANN as well as the logistic regression. (The results of the ANN would be compared to the logistic regression in order to show whether they could gain better results or not.) A case study to exhibit the applicability of the method is reported in the third section. Finally, a conclusion will be presented in the last section.

\section{RESEARCH DESIGN}

\section{A. Dimensions of Website Quality of Online Travel Agency}

In this study, there are six dimensions that have been used to assess the website quality of OTA, i.e., ease of use, security/privacy, information/content, responsiveness, visual appeal, and fulfillment [10]. These six dimensions are then divided into thirty-one attributes.

The first dimension is the ease of use. It is considered a critical component of a customer's decision to adopt a new information technology [28]. Many studies have shown that ease of use is an important determinant of the website quality (e.g., [13], [15], [29]). This dimension includes eight attributes, i.e., (i) the website always work correctly; accessibility of the website: (ii) it is easy to get around and find what I want on the website, (iii) the website does not waste my time, (iv) the website has well-arranged categories, (v) I can go to exactly what I want quickly, (vi) the search functions on the website are helpful, (vii) I can find what I want with a minimum number of clicks, and (viii) it is quick and easy to complete a transaction on the website.

Security/privacy is the second dimension. This dimension is not only identified as a major aspect of online transactions but also as a major barrier to online purchasing [30], [31]. It is defined as the degree to which a customer believes that using the website will be free from danger, risk, or doubt. This dimension consists of five attributes, i.e., (i) belief that the website has adequate security features, (ii) feel safe in the transaction with the website, (iii) feel the privacy is protected at the website, (iv) belief the website administrators will not misuse personal information, and (v) belief that the website will not give the information to other sites without permission.

The third dimension is information/content. It is believed that up-to-date and good quality of a web page play an important role in influencing customer's perception of website quality. The amount of information is also critical to attracting visitor to the website. It means that too much or too little information leads customer to bypass the page. Many studies pointed out that comprehensiveness, uniqueness, accuracy, entertainment value, and timeliness of information/content will increase customer's liking of the shopping experience (e.g., [32], [33]). This dimension comprises of four attributes, namely, (i) reliable information, (ii) complete information, (iii) relevant information, and (iv) up-to-date information.

Responsiveness, which is the fourth dimension, refers to the ability of online shopping to effectively manage problems aroused. It relates to the return policy as well as willingness to respond promptly to the requests of the customers. There are several studies that note this dimension as a crucial aspect in evaluating website quality (e.g., [34]-[36]). This dimension consists of five attributes: (i) the website is ready and willing to respond to customer needs, (ii) customer service personnel are always willing to help the customers, (iii) inquiries are answered promptly, (iv) when the customers have a problem, the website shows a sincere interest in solving it, and (v) the website appreciates customer's business.

The fifth dimension is visual appeal. The website's design or appearance is believed to be comparable to a physical store environment and has great influence on customer's perception. Web page design and aesthetics have been found to influence the perceived attractiveness of an electronic company [13], [29], [31]. Size and type of font, color combinations, animation, sound effect, and readability of the texts make a website not only visually attractive but also user-friendly. In this study, this dimension is divided into five attributes, i.e., (i) the website looks attractive, (ii) organized, (iii) the website uses multimedia features properly, (iv) uses colors properly, and (vi) fonts properly.

The last dimension is fulfillment. It refers to the delivery of products and/or services within a service level promised 错 误!未找到引用源。, [30], [35]. This dimension comprises of four attributes as follows: (i) the customers get what their booked from the website, (ii) the website gets bookings correct, (iii) the online receipt the customers get at the website informs them of the total charges that will be debited against their credit card, and (iv) it is easy to track the items the customer purchased through the website. Those six dimensions were then used to predict customer loyalty by employing the ANN approach which will be described briefly in the following subsection.

\section{B. The Artificial Neural Network}

To predict the customer loyalty, the ANN approach was employed. The concept of ANN originates from studies of the human brain. The human brain is described as highly complex, nonlinear, could process parallel and simultaneous information, and also believed to be many times faster than the fastest digital computers [37].

There are four assumptions in the ANN approach [38], i.e., 
(i) information processing occurs at many simple elements that are called neurons; (ii) signals are passed between neurons over connection links; (iii) each connection link has an associated weight, which, in a typical neural net, multiplies the signal transmitted; and (iv) each neuron applies an activation function (usually nonlinear) to its net input (sum of weighted input signals) to determine its output signal.

A typical ANN consists of three main elements (known as layers): the input layer, the hidden layer, and the output layer, see Fig. 1. Each layer is fully connected to the next layer. Except for the input layer, each neuron in the other layers has a nonlinear activation function. Each input is then multiplied by a weight and is added to the ones coming from the other input neurons; the result is added to a constant (known as bias). Then, the activation function is used to give the output of that specific hidden neuron. A similar set of operations is also performed for the output layer. The outputs of the hidden neurons are multiplied by the corresponding weights and added together and also to bias; the activation function of the output neuron is then used to give the output of the ANN model. A similar approach is followed when there are more model outputs (i.e., output layer neurons).

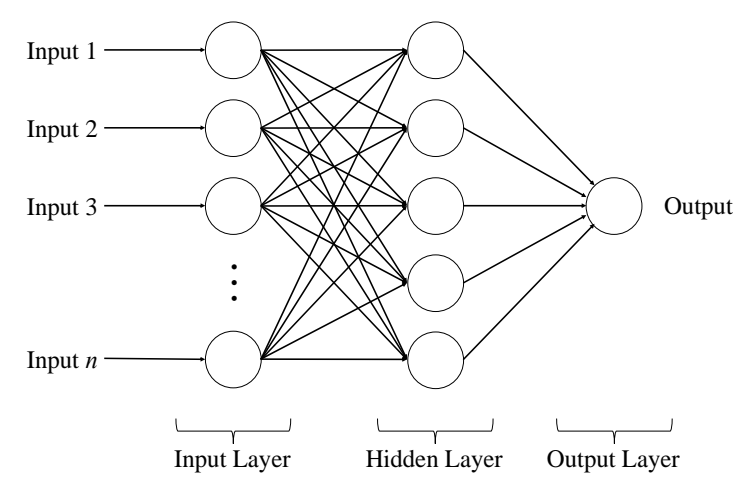

Fig. 1. A schematic of a simple ANN.

In a mathematical form, the neuron can be depicted with the pair of equations:

$$
\mu_{k}=\sum_{j=1}^{m} w_{k j} x_{j}
$$

and

$$
y_{k}=\varphi\left(\mu_{k}+B_{k}\right)
$$

where $u_{k}$ is the linear combiner output due to the input signal $k ; w_{k j}(j=1,2, \ldots, m)$ is the respective weights of neuron $k ; x_{j}$ $(j=1,2, \ldots, m)$ is the input signal; $y_{k}$ is the output signal of the neuron $k$; $\varphi$ is the activation function; and $B_{k}$ is the bias of neuron $k$.

The ANN offers many useful properties [37]:

1) Non-linearity. A neural network is made up of interconnected nonlinear neurons. Nonlinearity is an important property, especially when the physical mechanism responsible for generation of the inputs is inherently nonlinear.

2) Input-output mapping. A neural network learns from the examples by constructing an input-output mapping for the problem at hand. This approach is similar with a nonparametric statistical inference where the arbitrary decision boundaries in the inputs are estimated without invoking a probabilistic distribution model.

3) Adaptivity. Neural networks have a built-in capability to adapt their synaptic weights to changes in the surrounding environment. In particular, a neural network trained to operate in a specific environment can be easily retrained to deal with minor changes in the operating environmental conditions.

4) Evidential response. A neural network can be designed to provide information not only about which particular output to select, but also about the confidence in the decision made.

5) Contextual information. Knowledge is represented by the very structure and activation state of a neural network. Every neuron in the network is potentially affected by the global activity of all other neurons in the network. Consequently, contextual information is dealt with naturally by a neural network.

6) Fault tolerance. A neural network has a graceful degradation in performance rather than catastrophic failure. It implies that a neural network has the potential to be fault tolerant, or capable of robust computation.

7) VLSI implement-ability. The massively parallel nature of a neural network makes it potentially fast for the computation of certain tasks. This same feature makes a neural network well suited for implementation using very-large-scale-integrated (VLSI) technology.

8) Uniformity of analysis and design. Neurons, in one form or another, represent an ingredient common to all neural network; meaning that the network is possible to share theories and learning algorithms in many applications.

The overall model performance of ANN is commonly represented by two indicators, i.e., prediction rate and root mean square error (RMSE). The first is defined as the percentage of correctly predicting output vectors when the model is thoroughly trained. It can be calculated as $F / N$, where $F$ is the output vectors that are correctly predicted, and $N$ is the total output vectors to be predicted. The RMSE is measured by calculating the difference between the actual output and the model output as follows:

$$
R S M E=\sqrt{\frac{\sum_{i=1}^{n}\left(O_{a}^{i}-O_{m}^{i}\right)^{2}}{n}}
$$

where $O_{a}^{i}$ is the actual output for sample $i$ and $O_{m}^{i}$ is the model output for sample $i$.

\section{The Logistic Regression}

To gain more insight regarding the performance of the ANN, the results of the ANN model then would be compared with the logistic regression model results. The logistic regression is similar to multiple regression analysis in that one or more independent variables are used to predict a single dependent variable. What distinguishes a logistic regression model from multiple regression is that the dependent variable is nonmetric. It is preferable to 
discriminant analysis since the logistic regression can accommodate all types of independent variables (both metric and nonmetric) and do not require the assumption of multivariate normality [39]. The logistic regression is well-known used for classification and prediction problems, see for example [40]-[42].

The general model for the logistic regression is as follows:

$$
Y=\beta_{0}+\beta_{1} X_{1}+\beta_{2} X_{2}+\ldots++\beta_{n} X_{n}+\varepsilon,
$$

where $Y$ is the dependent variable, $X_{1}, X_{2}, \ldots X_{n}$ is the set of independent variables (in this research are the attributes of website quality of OTA), $\beta_{0}$ is a constant; $\beta_{j}$ is the regression coefficient $(j=1,2, \ldots, n)$, and $\varepsilon$ is an error term. Note that since there are three dependent variables, i.e., three dichotomous scaled questions of attitudinal measures of customer loyalty, hence, there are three different logistics regression models.

The predicted probabilities of the costumer belong to the certain group, i.e., 1 or 0 can be calculated using the formula for the cumulative distribution function of the standard logistic distribution. For example, the predicted probabilities of the customer belong to the group 1 is:

$$
\operatorname{Pr}(Y=1)=\frac{e^{b_{0}+b_{1} x_{1}+b_{2} x_{2}+\ldots+b_{n} x_{n}}}{1+e^{b_{0}+b_{1} x_{1}+b_{2} x_{2}+\ldots+b_{n} x_{n}}}
$$

where $b_{j}(j=0,1, \ldots, n)$ is an unbiased estimator of $\beta_{j}$. The value can be found by for example employing the method of maximum likelihood (see [43] for the detail).

The logistic function will always produce an $S$-shaped curve so regardless of the value of $X$ [44]. The logistic regression model has a logit model that is linear in $X$, therefore, it can only be effective for a linear model and have a low performance for a model that has a non-linear input. This is one of many different characteristics between a logistic regression and the ANN. Even though the ANN with no hidden layer is identical to a logistic regression model (if the activation function is sigmoidal) due to the nonlinearity in the hidden neuron, the output will be a nonlinear function of the inputs [45]. In a classification problem, it means that the decision boundary can be nonlinear as well, thus, the ANN is far more flexible that the logistic regression.

\section{CASE StUdy: Results AND Discussion}

The objective of this research is to predict the customer loyalty of an OTA according to the website quality dimensions using the ANN approach. The object of this research is 'OTA $Z$ ', an Indonesian-based OTA. A quantitative-based survey was conducted to accomplish the objective of the study. The survey consists of three parts. The first part aims to collect demographic data of the respondents, such as age, gender, and occupation. The second part utilizes the thirty-one attributes of the website quality. All the attributes were measured using the 5-point Likert scale, ranging from 1 which represents strongly disagree to 5 which represents strongly agree. The last part measures the customer loyalty by asking the respondents if they would: (i) recommend the OTA to others, (ii) revisit/reuse the services of the OTA, and (iii) provide a positive referral to others for the OTA.

The respondents of this survey were required to have experience in doing a transaction on the object of the research. The potential participants were first approached and asked if they agreed to participate in the survey. Four hundred twenty-five respondents have participated in this survey. The profile of the respondents is shown in Table I.

The reliability test with Cronbach's alpha [46] was conducted to verify if the respondents' answers for any questions tend to relate one and another. It has been proposed that the Cronbach's alpha can be viewed as the expected correlation of two tests that measure the same construct. By using this definition, it is implicitly assumed that the average correlation of a set of items is an accurate estimate of the average correlation of all items that pertain to a certain construct or dimension [47]. Suppose that we would like to measure a quantity of a dimension $\mathrm{W}$ which can be reflected as a sum of q attributes: $W=Z_{1}+Z_{2}+\ldots+Z_{q}$, the Cronbach's alpha is defined as [46]:

$$
\alpha=\frac{q}{q+1}\left(1-\frac{\sum_{i=1}^{q} \sigma_{Z_{i}}{ }^{2}}{\sigma_{W}{ }^{2}}\right)
$$

where $\sigma_{W}^{2}$ is the variance of the observed total test scores of each dimension and $\sigma_{Z i}^{2}$ is the variance of the attribute $i$ for the current sample. The results are shown in Table II. Note that all of the dimensions have the value of Cronbach's alpha more than 0.6 , indicated that the questionnaire being utilized is reliable [48].

The scores from the answers of the respondents when submitting the questionnaire of the OTA's website quality are used to develop an ANN model to predict customer loyalty. The model has six inputs that represent each dimension of website quality and one output for each attitudinal measure of customer loyalty; thus, three different models of neural network would be built based on those three different questions of attitudinal measures of customer loyalty. For the hidden layers and output layers, the sigmoid function is used as the activation function as follows:

$$
S(x)=\frac{e^{x}}{1+e^{x}}
$$

TABLE I: PROFILE OF THE RESPONDENTS

\begin{tabular}{llc}
\hline \hline \multicolumn{1}{c}{ Variables } & \multicolumn{1}{c}{ Categories } & Percentage (\%) \\
\hline \multirow{2}{*}{ Gender } & Male & 34.35 \\
\cline { 2 - 3 } & Female & 65.65 \\
\hline \multirow{4}{*}{$\begin{array}{l}\text { Age } \\
\text { (in years) }\end{array}$} & \multicolumn{1}{c}{15} & 0.24 \\
\cline { 2 - 3 } & $\mathbf{1 5 - 2 4}$ & 95.29 \\
\cline { 2 - 3 } & $\mathbf{4 5 - 3 4}$ & 3.06 \\
\cline { 2 - 3 } & $55-64$ & 0.94 \\
\cline { 2 - 3 } Occupation & $>65$ & 0.47 \\
\cline { 2 - 3 } & Freelancer & 0.94 \\
\cline { 2 - 3 } & Employee & 7.76 \\
\cline { 2 - 3 } & Self-employed & 0.48 \\
\cline { 2 - 3 } & Unemployed & 0.93 \\
\hline
\end{tabular}




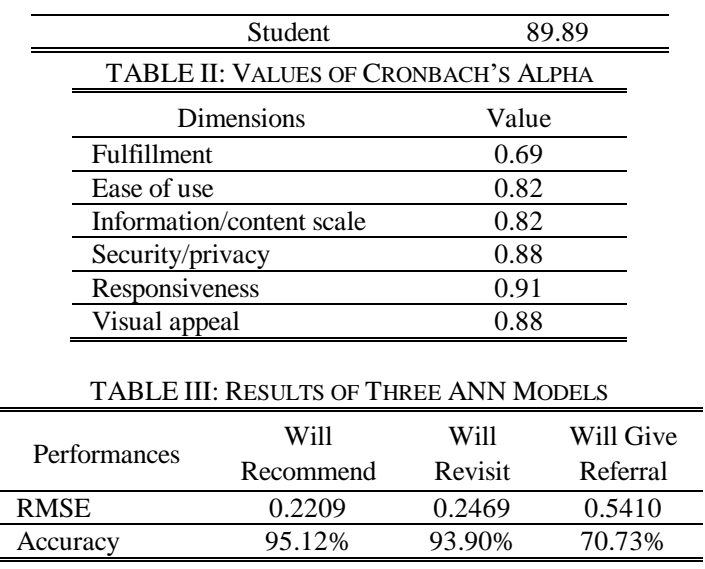

To design the ANN structure, it is necessary to determine the optimum number of neurons in the hidden layer. The number of optimum neurons is obtained by training and validating over a range of 1 to 60 hidden neurons. As shown in Fig. 2, the value of $R M S E$ decreased with the increased number of hidden neurons. A size of 20 hidden neurons is chosen to satisfy the trade-off between the model complexity and accuracy. In addition, the optimum number of training iterations are desired to avoid overfitting. Similar with the operations of obtaining the number of hidden neurons, the value of RMSE decreased as the number of iterations increased (see Fig. 3). The number of 200 training iterations is chosen in the end. All of the ANN models are depicted in Fig. 4, Fig. 5, and Fig. 6.

It is a common practice in ANN modeling to train and validate the model with two different datasets [37]. Initially, the ANN model is trained and tested with a large number of data (training data set). In this study, it is used $80 \%$ of the data as the training dataset. After meeting training accuracy requirements, the ANN model is validated using a smaller data set which previously was not used in training. The performance of the model is shown in Table III. The validation results show that the model is able to successfully predict customer loyalty.

The model can predict the customer's willingness to recommend the OTA with high accuracy $(95.12 \%)$. It also could predict the intention of the customer to revisit/reuse the services in the future with the value of RMSE 0.2469 and accuracy of $93.90 \%$. However, the model predicts the willingness of a customer to give a referral to others with only $70.73 \%$ accuracy and RMSE of 0.5410 .

The performance of three ANN models is then compared with the logistic regression model, which is a well-known statistical method to model dichotomously assessed dependent variables. The coefficients, as well as the performance of the logistic regression models, are shown in Table IV. Note that only the coefficients which are significant ( $\mathrm{p}$-value $<0.05$ ) are shown in the table. These findings show that the ANN models are more reliable than the logistic regression model to predict customer loyalty because it has higher accuracy and lower RMSE across all models. One of the reasons is that the ANN has a nonlinear network model, while the logistic regression postulates only a linearly additive regression function.

The high level of flexibility to model a complex problem suggest that the ANN could be a powerful alternative tool to the conventional statistical methods. However, as [21] pointed out, there are still some drawbacks from using the ANN to build a classification model. There is a lack of error distribution theory associated with the learning mechanism, thus, limits the derivation of statistical properties. The interpretation of the weights from each neuron is also a nontrivial task. The creation of an ANN model is usually open to interpretation. Trial and error are still widely used to construct the network properties, such as the number of the hidden neurons, the number of layers, the number of training iteration, etc.

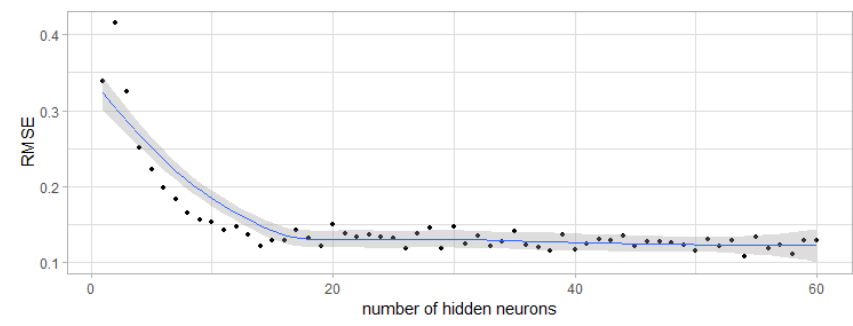

Fig. 2. Relationship between the number of hidden neurons with RMSE.

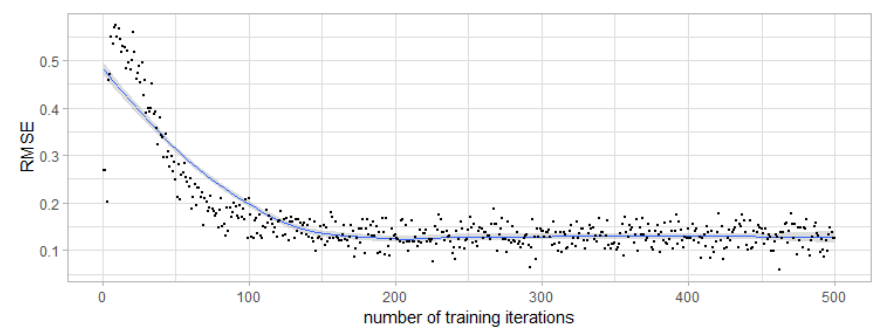

Fig. 3. Relationship between the number of training iterations with RMSE.

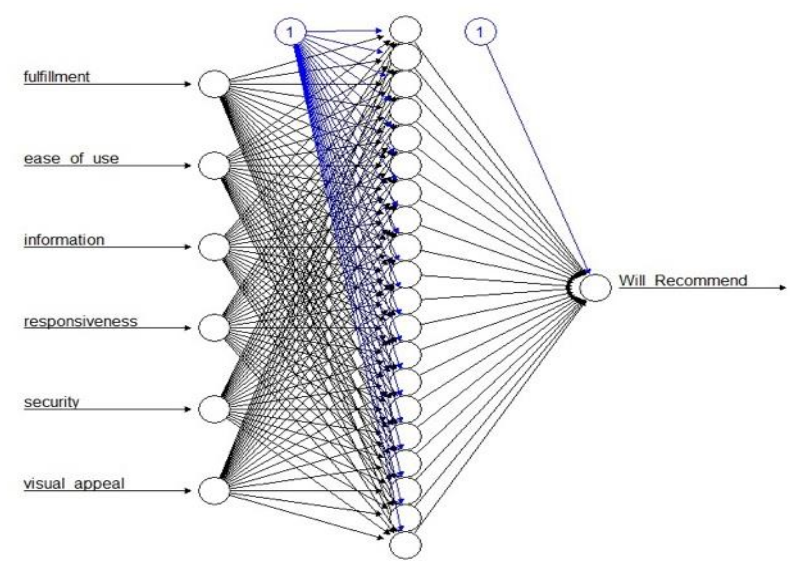

Fig. 4. The ANN model for "will recommend" loyalty measure.

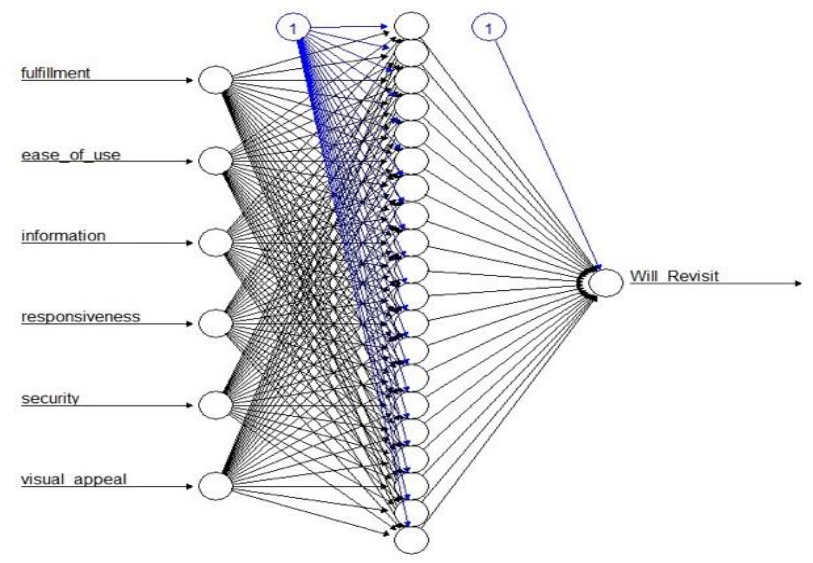


Fig. 5. The ANN model for "will revisit" loyalty measure.

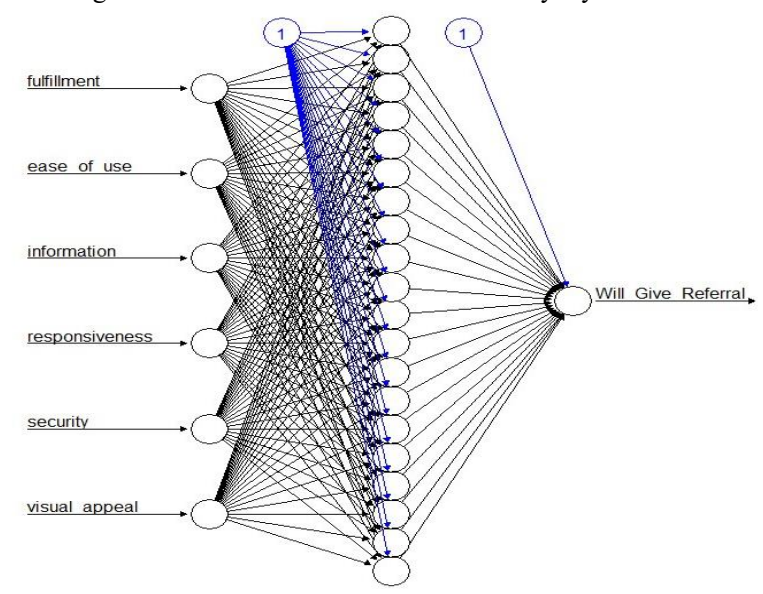

Fig. 6. The ANN model for "will give referral" loyalty.

TABLE IV: RESULTS OF LOGISTIC REGRESSION MODELS

\begin{tabular}{lccc}
\hline \hline \multicolumn{1}{c}{ Performances } & $\begin{array}{c}\text { Will } \\
\text { Recommend }\end{array}$ & Will Revisit & $\begin{array}{c}\text { Will Give } \\
\text { Referral }\end{array}$ \\
\hline Constant & -3.642 & 5.725 & -3.450 \\
\hline Fulfillment & -0.140 & -1.394 & 0.143 \\
\hline Ease of use & & -0.125 & \\
\hline Information/content & & 0.666 & \\
\hline Security/privacy & & 0.451 & \\
\hline Responsiveness & -0.195 & -0.303 & -0.082 \\
\hline Visual appeal & 0.491 & -1.393 & 0.117 \\
\hline RMSE & 0.5061 & 0.3492 & 0.6049 \\
\hline Accuracy & $74.39 \%$ & $87.80 \%$ & $63.41 \%$ \\
\hline \hline
\end{tabular}

\section{CONCLUSION}

The objective of this study was to predict customer loyalty of the OTA based on website quality dimensions using the ANN approach. Based on the theoretical perspective, this research was aimed to give such contribution to the literature of customers' loyalty prediction especially customer of OTA. By using the ANN approach, customer loyalty can be predicted using web quality dimensions (i.e., fulfillment, ease of use, information/content scale, security/privacy, responsiveness and visual appeal) as a set of independent variables. The dependent variables are represented by customers' willingness to recommend the services, to revisit/reuse the services in the future, and to give a positive referral to others.

The results of the ANN model which are shown in Table III outperforms the logistic regression models (shown in Table IV) in every dimension, since the results have higher accuracy and lower RMSE values. This suggests that the ANN models are more accurate for predicting consumer loyalty than the logistic regression models.

This study has important managerial implications. The developed model is reliable as an important evaluation tool for OTA, especially the website performance of the OTA. Because with this evaluation, the manager can determine what dimension to focus on to bring an improvement to the OTA's website and what dimension that already has a good performance in customers perspective to keep up the good performance.

The study also showed that fulfillment, ease of use, information/content scale, security/privacy, responsiveness and visual appeal all have effects on customer loyalty in OTA. Information/content was the strongest dimension that influences the customer to revisit the OTA. Complete and accurate information makes customers easier to select the customers' choices that suit their need. Security/privacy was the second strongest dimension. Because security/privacy of a website will make customers feels secure when they are sharing their personal information like credit card information, passport number, etc. which are a critical information needed to use the OTA services. Visual appeal was the third strongest dimensions. Because visual appeal of a website (interface) can be viewed as website' credibility that affect customers decision to use the OTA or not. The dimensions in this study could be a consideration for OTA in website evaluation and improvement.

\section{CONFLICT OF INTEREST}

The authors declare no conflict of interest.

\section{AUTHOR CONTRIBUTIONS}

Ulkhaq designed and revised the research, as well as wrote the paper; Adyatama collected the data, implemented the program, and analyzed the data; Fidiyanti, Rozaq, and Raharjo collected the data and wrote the paper. All authors had approved the final version.

\section{REFERENCES}

[1] A. S. Dick and K. Basu, "Customer loyalty: Toward an integrated conceptual framework," J. Acad. Mark. Sci., vol. 22, pp. 99-113, 1994.

[2] P. Kotler and K. L. Keller, Marketing Management, 14th ed. Upper Saddle River, N.J.: Prentice Hall, 2014.

[3] T. O. Jones and W. E. Sasser, "Why satisfied customers defect," Harvard Bus. Rev., vol. 73, pp. 88-99, 1995.

[4] F. Selnes, "An examination of the effect of product performance on brand reputation, satisfaction and loyalty," Eur. J. Mark., vol. 27, pp. 19-35, 1993.

[5] R. Hallowell, "The relationships of customer satisfaction, customer loyalty, and profitability: An empirical study", Int. J. Serv. Ind. Manag., vol. 7, pp. 27-42, 1996.

[6] F. F. Reichheld, "Learning from customer defections," Harvard Bus. Rev., vol. 74, pp. 56-69, 1996.

[7] R. T. Rust and A. J. Zahorik, "Customer satisfaction, customer retention, and market share," J. Retailing, vol. 69, pp. 193-215, 1993.

[8] F. F. Richard and W. E. Sasser, "Zero defection: Quality comes to services," Harvard Bus. Rev., vol. 68, pp. 105-111, 1990.

[9] T. Kompas. (2018). 'Indonesia' a largest 'online travel' market in Southeast Asia. [Online]. Available: https://tekno.kompas.com/read/2018/10/10/14210047/2025-pasar-onlin e-travel-indonesia-terbesar-di-asia-tenggara

[10] Y. Park, U. Gretzel, and E. Sirakaya-Turk, "Measuring web site quality for online travel agencies," J. Trav. Tour. Mark., vol. 23, pp. 15-30, 2007.

[11] B. Bai, R. Law, and I. Wen, "The impact of website quality on customer satisfaction and purchase intentions: Evidence from Chinese online visitors," Int. J. Hosp. Manag., vol. 27, pp. 391-402, 2008.

[12] S. Mithas, N. Ramasubbu, M. S. Krishnan, and C. Fornell, "Designing web sites for customer loyalty across business domains: A multilevel analysis," J. Manage. Inform. Syst., vol. 23, pp. 97-127, 2006.

[13] B. Yoo and N. Donthu, "Developing a scale to measure the perceived service quality of internet shopping sites (SITEQUAL)," Quart. J. Elect. Commerce, vol. 2, pp. 31-47, 2001.

[14] S. J. Barnes and R. T. Vidgen, "An integrative approach to the assessment of e-commerce quality," J. Elect. Commerce Res., vol. 3, pp. 114-127, 2002.

[15] E. T. Loiacono, D. Q. Chen, and D. L. Goodhue, "WebQualTM revisited: Predicting the intent to reuse a web site," in Proc. AMCIS 2002, 2002, pp. 301-309. 
[16] M. Wolfinbarger and M. C. Gilly, "eTailQ: Dimensionalizing, measuring and predicting etail quality," J. Retailing, vol. 79, pp. 183-198, 2003.

[17] H. H. Bauer, T. Falk, and M. Hammerschmidt, "eTransQual: A transaction process-based approach for capturing service quality in online shopping," J. Bus. Res., vol. 59, pp. 866-875, 2006.

[18] M. M. Ulkhaq, W. R. Wijayanti, A. Kusumawati, F. S. Aulia, R. S. Wijayanti, and R. Wiganingrum, "Combining the eTransQual scale and importance-performance analysis to assess service quality of online shopping," in Proc. International Conference on Industrial Engineering and Applications (ICIEA 2017), 2017, pp. 146-150.

[19] A. Parasuraman, V. A. Zeithaml, and A. Malhotra, "E-S-QUAL: A multiple-item scale for assessing electronic service quality," J. Serv. Res., vol. 7, pp. 1-21, 2005.

[20] M. M Ulkhaq, M. Rabbani, A. T. Wibowo, and B. A. Rachmania, "Assessing electronic service quality using E-S-QUAL and E-RecS-QUAL scales," ITMSOC Transactions on Innovation \& Business Engineering, vol. 2, pp. 20-26, 2017.

[21] S. H. Tsaur, Y.C. Chiu, and C. H. Huang, "Determinants of guest loyalty to international tourist hotels-A neural network approach," Tourism Manag., vol. 23, pp. 397-405, 2002.

[22] E. Guresen, G. Kayakutlu, and T. U. Daim, "Using artificial neural network models in stock market index prediction," Expert Syst. Appl., vol 38, pp. 10389-10397, 2010

[23] S. A. Kalogirou, "Applications of artificial neural-networks for energy systems," Applied Energy, vol. 67, pp. 17-35, 2000.

[24] A. Mellit and A. M. Pavan "A 24-h forecast of solar irradiance using artificial neural network: Application for performance prediction of a grid-connected PV plant at Trieste, Italy," Solar Energy, vol. 84, pp. 807-821, 2010.

[25] A. Y. L. Chong, B. Li, E. W. Ngai, E. Ch'ng, and F. Lee, "Predicting online product sales via online reviews, sentiments, and promotion strategies: A big data architecture and neural network approach," Int. J. Ope. Prod. Man., vol. 36, pp. 358-383, 2016.

[26] L. V. Fausett, Fundamental of Neural Networks, Englewood Cliffs, N.J.: Prentice Hall, 1994.

[27] P. K. Simpson, Artificial Neural Systems: Foundations, Paradigms, Application, and Implementation, Elmsford, N.Y.: Pergamon Press, 1990.

[28] F. D. Davis, "Perceived usefulness, perceived ease of use, and user acceptance of information technology," MIS Quart, vol. 13, pp. 319-340, 1989.

[29] P. V. Schaik and J. Ling, "Five psychometric scales for online measurement of the quality of human-computer interaction in web sites," Int. J. Hum-Comput. Int., vol. 18, pp. 309-322, 2005.

[30] J. M. Field, G. R. Heim, and K. K. Sinha, "Managing quality in the e-service system: Development and application of a process model," Prod. Oper. Manag., vol. 13, pp. 291-306, 2004.

[31] C. Shchiglik and S. J. Barnes, "Evaluating web site quality in the airline industry," J. Comput. Inform. Syst., vol. 44, pp. 17-25, 2004.

[32] A. M. Aladwani and P. C. Palvia, "Developing and validating an instrument for measuring user-perceived web site quality," Information and Manag., vol. 39, pp. 467-476, 2002.

[33] S. Kaynama and C. Black, "A proposal to assess the service quality of online travel agencies: An exploratory study," J. Prof. Serv. Mark., vol. 21, pp. 63-88, 2000.

[34] M. Long and C. McMellon, "Exploring the determinants of retail service quality on the Internet," J. Serv. Mark., vol. 18, pp. 78-90, 2004.

[35] V. A. Zeithaml, A. Parasuraman, and A. Malhotra, "Service quality delivery through Web sites: A critical review of extent knowledge," $J$. Acad. Market. Sci., vol. 30, pp. 362-375, 2002.

[36] Z. Yang and M. Jun, "Consumer perception of e-service quality: From Internet purchaser and non-purchaser perspectives," J. Bus. Strateg., vol. 19, pp. 19-41, 2002.

[37] S. Haykin, Neural Network and Learning Machines, 3rd ed. Upper Saddle River, N.J.: Prentice Hall, 2009.

[38] O. M. Rezapour, L. T. Shui, and D. B. Ahmad, "Review of artificial neural network model for suspended sediment estimation," Australian $J$. Basic Appl. Sci., vol. 4, pp. 3347-3353, 2010.

[39] J. F. Hair, W. C. Black, B. J. Babin, and R. E. Anderson, Multivariate Data Analysis, 7th ed. London: Pearson, 2014.

[40] M. M. Ulkhaq, A. K. Widodo, M. F. A. Yulianto, Widhiyaningrum, A. Mustikasari, P. Y. Akshinta, "A logistic regression approach to model the willingness of consumers to adopt renewable energy sources," IOP Conf. Ser.: Earth Environ. Sci., vol. 127, p. 012007, 2018.

[41] E. Sardianou and P. Genoudi, "Which factors affect the willingness of consumers to adopt renewable energies?" Renewable Energy, vol. 57, pp $1-4,2013$.

[42] L. A. Brahim and M. Elmoulat, "Application of logistic regression method to produce landslide susceptibility map: A case study of Tetouan
Mazari, Morocco," in Proc. MATEC Web of Conference, 2018, vol. 149 p. 02082.

[43] P. McCullagh and J. A. Nelder, Generalized Linear Models, vol. 2 , London: Chapman and Hall, 1989.

[44] G. James, D. Witten, T. Hastie, and R. Tibshirani, An Introduction to Statistical Learning with Application in R, New York: Springer, 2013.

[45] S. Dreiseitl and L. Ohno-Machado, "Logistic regression and artificial neural network classification models: A methodology review," $J$. Biomedical Information, vol. 35, pp. 352-359, 2003.

[46] L. J. Cronbach, "Coefficient alpha and the internal structure of tests," Psychometrika, vol. 16, pp. 297-334, 1951.

[47] J. C. Nunnally and I. H. Bernstein, Psychometric Theory, 3rd ed. New York, N.Y.: McGraw-Hill, 1994

[48] J. Nagpal, A. Kumar, S. Kakar, and A. Bhartia, "The development of 'Quality of Life Instrument for Indian Diabetes patients (QOLID)': A validation and reliability study in middle and higher income groups," $J$. Assoc. Physicians India, vol. 58, pp. 295-304, 2010.

Copyright $(\odot 2020$ by the authors. This is an open access article distributed under the Creative Commons Attribution License (CC BY-NC-ND 4.0), which permits use, distribution and reproduction in any medium, provided that the article is properly cited, the use is non-commercial and no modifications or adaptations are made.

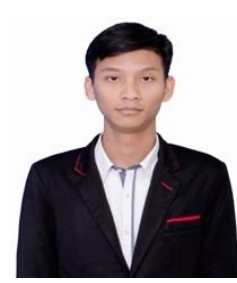

M. Mujiya Ulkhaq is currently a lecturer. He is now in the Department of Industrial Engineering of Diponegoro University, Indonesia. His research of interests includes service and quality management, multi-criteria decision making, and consumer behavior

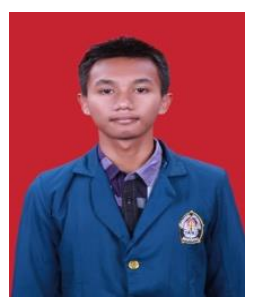

Arga Adyatama was born in Indonesia on February 04, 1997. $\mathrm{He}$ is an undergraduate student in Department of Industrial Engineering, Diponegoro University, Indonesia. He is a member of the board of Industrial Engineering Student's Association.

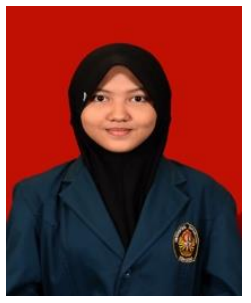

Finsaria Fidiyanti was born in Indonesia on July 24 1997. She is an undergraduate student in the Department of Industrial Engineering, Diponegoro University, Indonesia. She is a member of the board of Industrial Engineering Student's Association.

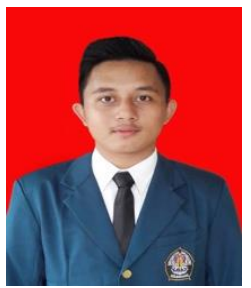

Riyan Rozaq was born in Indonesia on August 15 1998. He is an undergraduate student in the Department of Industrial Engineering, Diponegoro University, Indonesia. He is a member of the board of the Industrial Engineering Student's Association.

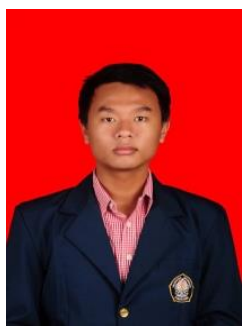

M. Fauzan M. Raharjo was born in Indonesia on April 12, 1997. He is an undergraduate student in Department of Industrial Engineering, Diponegoro University, Indonesia. He is a member of the board of the Industrial Engineering Student's Association. 